\title{
CLINICAL STUDY REGARDING THE REHABILITATION TREATMENT OF OSTEOPOROTIC PATIENTS
}

\author{
FLORIN-MIHAI MARCU ${ }^{1}$, LIVIU LAZĂR ${ }^{1}$, FELICIA CIOARĂ ${ }^{1}$, SEBASTIAN NEMETH ${ }^{2 *}$, \\ SIMONA BUNGĂU ${ }^{2}$, FLORIN BĂNICĂ ${ }^{2}$ \\ ${ }^{I}$ Department of Psycho-neurosciences and Recovery, Faculty of Medicine and Pharmacy, University of Oradea, 410087, \\ Oradea, Romania \\ ${ }^{2}$ Department of Pharmacy, Faculty of Medicine and Pharmacy, University of Oradea, 410028, Oradea, Romania
}

*corresponding author: sebinemeth@yahoo.com

Manuscript received: September 2020

\begin{abstract}
Osteoporosis, a major skeletal disorder characterized by decreased bone mass, predominantly affects women and has a major impact on public health. Fractures due to bone fragility are the most important complications of osteoporosis. The main objectives of the optimal management of osteoporosis are to increase muscle strength and strengthen bones, respectively to reduce the risk of falls, trauma and fractures. In the rehabilitation treatment of osteoporotic patients, physical therapy is essential. In this study we aimed to demonstrate that the treatment of osteoporosis by combining the drugs with a physical therapy program for one year has superior therapeutic effects compared to the simple drug treatment performed in the same period of time. Two groups of patients were enrolled: the study group (39 subjects who underwent home physiotherapy) and the control group (43 subjects who did not undergo home physiotherapy). The results highlighted the superior therapeutic benefits of drug treatment associated with an appropriate physical therapy program.
\end{abstract}

\section{Rezumat}

Osteoporoza, un dezechilibru major caracterizat prin scăderea masei osoase, afectează predominant femeile şi are un impact major asupra sănătății publice. Fracturile datorate fragilității osoase sunt cea mai importantă complicație a osteoporozei. Principalele obiective ale unui management optim al osteoporozei sunt creșterea forței musculare și întărirea osului, respectiv reducerea riscului de căderi, traume și fracturi. În tratamentul de reabilitare al pacienților osteoporotici, kinetoterapia este esențială. În acest studiu ne-am propus să demonstrăm că tratamentul osteoporozei prin combinarea unui tratament medicamentos cu un program de kinetoterapie, timp de un an, are efecte terapeutice superioare comparativ cu tratamentul simplu medicamentos efectuat în aceeaşi perioadă de timp. Au fost inrolate două grupuri de pacienți: grupul de studiu (39 de subiecți care respectă kinetoterapia acasă) și grupul de control (43 subiecți care nu respectă kinetoterapia acasă). Rezultatele evidenţiază beneficiile terapeutice superioare ale tratamentului medicamentos asociat cu un program adecvat de kinetoterapie.

Keywords: osteoporosis, rehabilitation treatment, kinetotherapy

\section{Introduction}

Osteoporosis is a bone disease characterized by a decrease in bone strength, evidenced by qualitative parameters as follows: bone micro-architecture, bone trabeculae and bone mineral density (BMD), decreased trabecular count; the consequence of decreasing bone strength is represented by an increased bone fragility and fracture risk [22]. BMD is a quantitative parameter of bone composition and has an age-dependent dynamics: it grows from childhood to 25 - 30 years of age (when it is considered as being maximum), goes through a plateau to 45 - 50 years, and then decrease with $0.5-1 \%$ per year; this loss is related to age. The decline in BMD is more pronounced in the post menopause when, due to oestrogen collapse, the bone mineralization suddenly decreases and a diminishing in bone density of $>1 \%$ can occur consecutively [ 27 , $28]$. Rehabilitation treatment is of great importance in patients with osteoporosis because it contributes both to increase the level of functionality and independence and to improve the quality of life of the patient suffering of this disease. This treatment usually includes kinetotherapy, electrotherapy, thermotherapy, hydro-kinetotherapy, psychotherapy and measures to prevent falls and to increase the postural stability [6, 25]. In establishing and managing an optimal treatment, physiotherapy has a relevant role, because, according to specialized studies, it can not only prevent osteoporosis, but can alleviate it, when the pathology is already installed [10]. In osteoporotics, the recommended physical therapy program in the hospital should be followed by patients after discharge; they will repeat the physical therapy program at least three times a week; the intensity of the exercises, at the beginning of the program, will depend on the physical capacity of the patients, and will be intensified by 
increasing the number of repetitions, being directly dependent on the subject's resistance to movement, respectively to physical effort [3].

The objective of this study was to highlight the effectiveness of the kinetotherapy program in the treatment of patients with osteoporosis. Early diagnosis of the disease and the combination of a realistic medical treatment with a complex kinetotherapy program and measures to prevent falls and increase postural stability are followed by an increase in the quality of life of the osteoporotic patient $[24,26]$.

\section{Materials and Methods}

\section{Study design}

Subjective and objective anamnestic criteria were established and followed in the study for 82 patients admitted to "Băile Felix" Medical Rehabilitation Clinical Hospital (Bihor, Romania), between 2014 and 2017. Patients who had no previous treatment for osteoporosis before the hospitalization were recruited and all of them signed an informed consent prior to hospital admission. The study was conducted according to the WMA Declaration of Helsinki - Ethical Principles for Medical Research involving Human Subjects (1975), last amended in Brazil, in October 2013, and it was approved by the Ethics Committee of the hospital. The criteria for patients' inclusion in research were as follows: hospitalization and treatment for 14 days in the hospital mentioned above; the diagnosis of primary osteoporosis, confirmed by the DEXA examination; compliance with drug therapy during the study; observance of the monitored parameters at the initial and final evaluation.

Conservative/non-surgical treatment included medical treatment, rehabilitation treatment and a lifestyle that did not favour the onset/evolution of osteoporosis. The drug treatment was represented by anti-osteoporotic drugs; Ca/vitamin D supplements, if needed; antipain drugs, if needed; medications necessary for pathologies that can cause imbalance of walking/ standing, if needed. Rehabilitation treatment included program of physical exercise or kinetotherapy; electrotherapy procedures, depending on the symptomatology (TENS, interferential currents, ionic galvanizations); thermotherapy procedures, depending on the symptomatology (paraffin, ice massage); hydro-kinetotherapy; psychotherapy; measures to prevent falls and increase postural stability. The kinetotherapy program recommended during hospitalization was conducted under the guidance of a specialized physical therapist; to be effective, the physical exercises were performed once a day, at least 5 times per week, with varying intensity depending on the physical capacity of each patient. In osteoporosis, the kinetotherapy program has the following objectives: correcting posture and alignment of body segments; increasing in physical and muscle strength; regaining of the balance and coordination; cardiac effort training; respiratory re-education.

Characteristic in patients with osteoporosis is that the kinetotherapy program, as well as the medical treatment, should not be interrupted with the discharge of the patient; it should be continued at home, throughout the entire patient's life. The indication of compliance and adherence to the physical therapy program at home, after discharge, was not respected by all 82 patients in the study. Depending on this fact, the subjects were divided into two groups: (1) the group that underwent kinetotherapy at home (study group), comprising 39 subjects; (2) the group that didn't undergo kinetotherapy at home (namely the control group), comprising 43 subjects.

In order to highlight the superior therapeutic efficacy, in the treatment of osteoporosis, regarding the association of drug treatment with physical therapy compared to the simple drug treatment, the following objective parameters were followed, for one year: the height difference, the T-score and the fractures of fragility. The height difference of the patient during the study. The evaluation was performed using a standard taliometer, the same device being used in each of the patients. The value of this parameter (expressed in centimetres), was obtained by subtracting the height at the end of the study (after one year of treatment), from the initial height (before the start of the study). The $T$-score that expresses bone mineral density, obtained by examining DEXA at admission and after one year of treatment. This score is calculated based on the difference between the patient's BMD and the mean BMD of a healthy adult population of sex and race relative to the standard deviation of the respective population:

$\mathrm{T}$-score $=($ patient BMD - average young healthy population BMD)/(standard deviation of the population).

The fractures of fragility. To perform this assessment, all patients were radiographically examined at the beginning and after one year of treatment.

Statistical analysis

Statistical processing was performed using Excel 2003, SPSS 1996, MedCalc version 8. Parametric tests were used to describe and compare the two groups, due to the normal distribution of patients: Student's $t$ test, the Fisher test and the Chi-square test. The relative risk (R.R.) and odds ratio (O.R.) for the new fragility fractures were calculated both in the group with physical therapy and in the group without physical therapy. The level of significance was set, regardless of the statistical method applied, was $\mathrm{p}<0.05$.

\section{Results and Discussion}

The analysis of the two groups involved the comparative and evolutionary analysis of both studied groups. By comparing the initial values, we assessed whether 
there are statistically significant differences between the two groups studied, whether or not the groups are homogeneous before treatment. The final values of the monitored parameters allowed to observe which of the two types of recommended treatment (simple drug or drug associated with physical therapy) has a stronger therapeutic impact. Through the evolutionary analysis of each group, in our study, it was highlighted the therapeutic impact of the two types of treatment on the following parameters: BMD assessed by $\mathrm{T}$ score and the frequency of fragility fractures during treatment. Initially, it was performed an analysis of the two groups in terms of the gender, age and the origin of patients (Table I). In terms of demographic characteristics, there are no significant differences between the groups $(p>0.05)$, however the percentage of patients in the study group from urban areas is significantly higher than those in the control group (69.24\% vs. 46.51\%, p = 0.039). Afterwards, both groups were evaluated in terms of the evolution of the objective parameters: number of fragility fractures, the value of the $\mathrm{T}$ score and the height difference during the study.

Table I

General characteristics of the groups

\begin{tabular}{|c|c|c|c|}
\hline \multicolumn{2}{|c|}{$\begin{array}{c}\text { Characteristics of the } \\
\text { groups }\end{array}$} & \multirow{3}{*}{$\begin{array}{c}\text { Average } \pm \text { SD } \\
60.15 \pm 5.60 \\
62.30 \pm 6.40 \\
\end{array}$} & \multirow{3}{*}{$\begin{array}{c}\mathbf{p} \\
0.111\end{array}$} \\
\hline \multirow{2}{*}{$\begin{array}{c}\text { Age } \\
\text { (years) }\end{array}$} & \begin{tabular}{|l|} 
Study \\
\end{tabular} & & \\
\hline & Control & & \\
\hline \multirow{2}{*}{$\begin{array}{c}\text { Gender } \\
(\%)\end{array}$} & Study & F/M: 64.10/39.90 & \multirow{2}{*}{0.653} \\
\hline & Control & F/M: 58.14/41.86 & \\
\hline \multirow{2}{*}{$\begin{array}{c}\text { Environment } \\
\text { origin }(\%)\end{array}$} & Study & U/R: $69.24 / 30.77$ & \multirow{2}{*}{0.039} \\
\hline & Control & U/R: $46.51 / 53.49$ & \\
\hline
\end{tabular}

The prevalence of fragility fractures was weakly significantly higher in the patients included in the control group, respectively those who do not undergo physical therapy at home $(76.74 \%$ vs. $56.41 \%$, p = 0.052 ). Instead, the risk of fragility fractures is clearly higher, respectively 2.6 times higher in patients in the control group compared to those in the study group $(\mathrm{OR}=2.550,95 \% \mathrm{CI}: 0.987-6.589, \mathrm{p}=0.053)$ (Table II).

Table II

Prevalence of fragility fractures in the studied

\begin{tabular}{|c|c|c|}
\hline $\begin{array}{c}\text { Fragility } \\
\text { fractures }\end{array}$ & $\begin{array}{c}\text { Study group } \\
\text { No. of cases (\%) }\end{array}$ & $\begin{array}{c}\text { Control group } \\
\text { No. of cases (\%) }\end{array}$ \\
\hline YES & $22(56.41)$ & $33(76.74)$ \\
\hline NO & $17(43.59)$ & $10(23.26)$ \\
\hline Odds ratio (OR) $=2.550$ & Chi-square test $=3.781$ \\
IC $95 \%=0.987-6.589 ;$ & $p=0.052$ \\
$p=0.053$ & \\
\hline
\end{tabular}

Analysing the initial and final values of the $\mathrm{T}$ score, it was found that there were no statistically significant differences between the groups (Table III). From the evolution point of view, compared to the initial value, in both groups, the $\mathrm{T}$ score decreased insignificantly at the final evaluation $(-3.205$ vs. $-3.210, \mathrm{p}=0.961$, respectively $-3.211 v s .-3.223, \mathrm{p}=0.901)$. Comparing the two groups, we noted that, both $\mathrm{T}$ scores (at the initial and final evaluation), were insignificantly higher in the control group compared to the study group $(-3.211$ vs. $-3.205, \mathrm{p}=0.951$, respectively $-3.223 v s$. $-3.210, \mathrm{p}=0.897)$.

Table III

Initial and final values for BMD in the two groups

\begin{tabular}{|c|c|c|c|}
\hline \multirow{2}{*}{ T Score } & Study group & Control group & \multirow{2}{*}{ p } \\
\cline { 2 - 3 } & \multicolumn{2}{|c|}{ Mean \pm SD } & \\
\hline Initial & $-3.205 \pm 0.447$ & $-3.211 \pm 0.440$ & 0.951 \\
\hline Final & $-3.210 \pm 0.454$ & $-3.223 \pm 0.449$ & 0.897 \\
\hline p & 0.961 & 0.901 & \\
\hline
\end{tabular}

Comparing the height differences of the patients in the two groups, after one year of treatment, it was found a statistically significant difference $(p<0.05)$ in favour of the patients in the control group. At the end of the study, the difference in height of the patients in the control group was significantly higher than the difference in height recorded in the study group $(1.383 \mathrm{~cm}$ in the control group $v s$. $1.023 \mathrm{~cm}$ in the study group, $\mathrm{p}=0.026$ ).

It is well known that osteoporosis, due to the fact that women usually have a longer average lifespan, thinner bones and postmenopausal accentuated bone loss, predominantly affects females. This disease also occurs in men, but to a lesser extent; this aspect was also highlighted in other studies, and it was also established in the current study [1]. According to other published data $[12,16,18]$, there are several risk factors for osteoporosis in the urban environment compared to rural areas: decreases the age of menopause, increases sedentary, increases alcohol consumption, coffee, cigarettes and lower consumption of dairy products. According to some results [20], the maximum incidence of osteoporosis for women is between 55 64 years, including both postmenopausal bone loss and the beginning of the bone loss during the period of senescence.

In some studies, it is considered that a body mass index $(B M I=G \backslash T 2)$ of less than $20 \mathrm{~kg} / \mathrm{m}^{2}$, more common in urban areas, is a significant risk factor in osteoporosis [5, 13]. At the end of the study, after one year of treatment, the patients in the control group had a higher risk of fragility fracture and a relative risk for fracture compared to patients in the study group $(\mathrm{OR}=2.550,95 \% \mathrm{CI}=0.9869-6.5889$, $\mathrm{RR}=1.3605,95 \% \mathrm{CI}=0.9867-1.8758)$. It clearly results in the positive impact of physical therapy, given the specific physical exercises following falls with consecutive fractures due to fragility. Our results are confirmed by other studies [8, 11]. The presence of a fragility fracture in the history of a patient with osteoporosis will determine a risk for a new fragility fracture, increasing more than twice 
the risk of a new fragility fracture $v s$. the patients without presenting fragility fractures in their history. This risk is reflected in the fact that many patients have suffered more than one osteoporotic fracture; the risk of a new fragility fracture is higher in the first year after the first fracture and the risk of recurrence remains significant in the next five years after the initial fracture [19].

Decreasing in height with aging is a natural phenomenon, but a loss of five centimetres or more, at maturity, is a warning sign for a potential diagnosis of osteoporosis [23]. According to Bord-Hoffman, there are two major causes that lead to a decrease in height in elderly people. The first is represented by the degenerative changes of the intervertebral discs (as the patient ages, they lose their elasticity, become dehydrated, compress and, as a consequence, the subjects become less tall). The other major cause of the decrease in height with age is the vertebral fractures due to osteoporosis, being accompanied by spine pain and spine modifications [4]. In order to get a clearer picture of the impact of kinetotherapy on patients with osteoporosis, in our study we compared the height difference between the height at the beginning and at the end of the study.

Our results highlighted the impact of kinetotherapy on fractures of fragility. Patients from kinesitherapy group, due to daily compliance with the recommended physical exercise program, showed both a lower decrease of height and a less risk for fragility fracture compared to patients in the group without kinetotherapy. Kinetotherapy exercises play a decisive role in increasing bone strength, the lack of physical activity being followed by a decreasing in BMD and thinning of the cortical bone in the diaphysis area. Specifically, a paralyzed member loses about $10 \%$ of the bone mass per year, equivalent to 20 years of bone loss [2]. The stimulus required by the bone to maintain its structural and functional force is the pressure exerted on it. To have an osteogenic effect, physical exercises should result in muscle contractions that are intense enough to cause dynamic tension on the bone, diversified over time [9]. Due to the fact that osteoporosis is characterized by reduced BMD, we considered it appropriate to evaluate the impact of kinetotherapy on osteoporotic bone density. Analysing both groups, it was observed that from the point of view of BMD, they were homogeneous before and at the end of the study (initial $\mathrm{p}=0.9473$; final $\mathrm{p}=0.896$ ).

It is noted that the homogeneity of the two groups, in terms of BMD, was maintained after one year (period of time in which the two groups have undergone different treatments: kinetotherapy associated with drug treatment or drug treatment only). According to our results, confirmed by other data [15] as well, in primary osteoporosis, kinetotherapy associated with drug treatment will not result in a statistically significant improvement in BMD compared to solitary drug therapy. Analysing the evolution of the 2 groups, BMD evolves the same. At the end of the study, lower values were recorded compared with the values at the start of the study, but there were no significant differences in either groups. For a clearer picture of the effect that the two types of treatment have on bone strength, it was calculated for each group the mean bone loss occurred during the study. Thus, in the patients with drug therapy associated with kinetotherapy (BMD difference $=0.005$, base-line $\mathrm{BMD}=-3.205$, final BMD $=-3.21$ ), an average bone loss of $0.15 \%$ was found during the study. In the drug-only treatment group $(\mathrm{BMD}$ difference $=0.012$, baseline $\mathrm{BMD}=$ 3.211 , final $\mathrm{BMD}=-3.223$ ), an average bone loss of $0.37 \%$ was found during the study. According to other researchers, the mean BMD decrease rate in men, aged 45 - 84 years, is about $0.5 \%$ [7]. Other published data have shown that the amount of this loss increases proportionally to age [21]; if in men of about 45 years it is between $0.38-0.77 \%$, in men of 75 years it is between $0.52-0.90 \%$. In women aged 45 - 84 years, it was claimed that BMD decreases on average by about $0.9 \%$ per year. In patients with primary osteoporosis, the limit of kinetotherapy on BMD was also highlighted [14]. An explanation in this regard can be considered the fact that if anti-osteoporotic drugs have an anti-resorptive effect preventing bone resorption by osteoclasts, kinetotherapy has an osteogenic effect on osteoblasts and osteocytes. Osteogenic effect of kinetotherapy is inversely proportional to age; as the patient's age is advanced, the effect of physical therapy is limited due to changes in cellular senescence - decreases the number and activity of osteoblasts and osteoclasts. It follows that kinesitherapy in primary osteoporosis has only a limiting effect, inhibiting the decrease in BMD. The osteogenic effect of kinetotherapy is limited in primary osteoporosis mainly due to the age of patients; the higher the age of patients, the lower the kinetotherapy effect on bone density. Zehnacker argues that the duration of physical exercise/physical therapy should be at least one year to cause changes in BMD [29]. The duration of specific exercise is important because the total training time of a basic multicellular unit for bone is $4-6$ months, the duration of the specific physical exercise to be effective on BMD should be at least $2-3$ times more than this period (12 - 18 months). Other specialists argue that the duration of physical therapy, to be effective in osteoporosis, should be over one year, considering the modelling/ remodelling process to which bone is subjected during specific exercises [17].

\section{Conclusions}

Patients with osteoporosis who undergo for one year, the combination of kinetotherapy with drug treatment 
on a daily basis, have the following advantages compared to the patients who only followed drug treatment: increase in muscle tone and postural stability; improving the quality of life, due to the decrease of kyphotic changes and the number of vertebral fractures characteristic of osteoporosis; modulating the decrease of BMD. It should be noted that, between the benefits of kinetotherapy and the age of patients, there is a ratio of inverse proportionality. Therefore as the patient is older, the benefits of kinetotherapy in osteoporosis are lower.

\section{Conflict of interest}

The authors declare no conflict of interest.

\section{References}

1. Adler RA, Osteoporosis in men: a review. Bone Res., 2014; 2 : 14001: 1-8.

2. Beaupre GS, Lew HL, Bone-density changes after stroke. Am J Phys Med Rehabil., 2006; 85(5): 464-472.

3. Benedetti MG, Furlini G, Zati A, Mauro GL, The effectiveness of physical exercise on bone density in osteoporotic patients. Biomed Res Int., 2018; 2018: 4840531: 1-10.

4. Cavalu $\mathrm{S}$, Simion $\mathrm{V}$, Bănică $\mathrm{F}$, In vitro study of collagen coating by electrodeposition on acrylic bone cement with antimicrobial. Digest J Nanomat Biostruct., 2010; 6(1): 89-97.

5. De Laet C, Kanis J, Oden A, Johanson H, Johnell O, Delmas P, Eisman J, Kroger H, Fujiwara S, Garnero P, McCloskey E, Mellstrom D, Melton L, Meunier P, Pols H, Reeve J, Silman A, Tenenhouse A, Body mass index as a predictor of fracture risk: A metaanalysis. Osteoporos Int., 2005; 16(11): 1330-1338.

6. Dionyssiotis Y, Skarantavos G, Papagelopoulos P, Modern Rehabilitation in Osteoporosis, Falls, and Fractures. Clin Med Insights Arthritis Musculoskelet Disord., 2014; 7: 33-40.

7. Emaus N, Berntsen GJ, Joakimsen R, Fonnebø V, Longitudinal changes in forearm bone mineral density in women and men aged 45-84 years, The Troms $\varnothing$ Study, a Population-based Study. Am J Epidemiol., 2006; 163(5): 441-449.

8. Faibish D, Ott S, Boskey A, Mineral changes in osteoporosis. Clin Orthop Relat Res., 2006; 443 : 28-38.

9. Fernandes Moreira LD, Longo de Oliveira M, LiraniGalvão AP, Villa Marin-Mio R, Nolasco dos Santos R, Lazaretti-Castro M, Physical exercise and osteoporosis: effects of different types of exercises on bone and physical function of postmenopausal women. Arq Bras Endocrinol Metab., 2014; 58(5): 514-522.

10. Gregg EW, Pereira MA, Caspersen CJ, Physical Activity, Falls and Fractures Among Older Adults, A Review of the Epidemiologic Evidence. $J$ Am Geriatr Soc., 2000: 48(8): 883-893.

11. Gunendi Z, Ozyemisci-Taskiran O, Demirsoy N, The effect of 4-week aerobic exercise program on postural balance in postmenopausal women with osteoporosis. Rheumatol Int., 2008, 28(12): 1217-1222.

12. Hien VT, Khan N, Lam N, Mai L, Le DN, Nhung B, Nakamori M, Kunii D, Sakai T, Yamamoto S,
Determining the prevalence of osteoporosis and related factors using quantitative ultrasound in Vietnamese adult women. Am J Epidemiol., 2005; 161(9): 824-830.

13. Kanis JA, Borgstrom F, De Laet C, Johansson H, Johnell O, Jonsson B, Oden A, Zethraeus N, Pfleger B, Khaltaev N, Assessment of fracture risk. Osteoporos Int., 2005; 16: 581-589.

14. Korpelainen R, Korpelainen J, Heikkinen J, Väänänen $\mathrm{K}$, Keinänen $\mathrm{K}$, Lifelong risk factors for osteoporosis and fractures in elderly women with low body mass index-a population-based study. Bone, 2006; 39(2): 385-391.

15. Maddalozzo GF, Widrick J, Cardinal B, WintersStone Kerri, Hoffman M., Snow Christine, The effects of hormone replacement therapy and resistance training on spine bone mineral density in early postmenopausal women. Bone, 2007; 40(5): 1244-1251.

16. Matsuzaki M, Pant R, Kulkarni B, Kinra S, Comparison of Bone Mineral Density between Urban and Rural Areas: Systematic Review and Meta-Analysis. PLoS One, 2015; 10(7): e0132239: 1-11.

17. Pellikaan P, Giarmatzis G, Vander Sloten J, Verschueren S, Jonkers I, Ranking of osteogenic potential of physical exercises in postmenopausal women based on femoral neck strains. PLoS One, 2018; 13(4): e0195463: 1-18.

18. Rafał SF, Osteoporosis risk factors in rural and urban women from the Lublin Region of Poland. Ann Agric Environ Med., 2005; 12(1): 21-26.

19. Reginster JY, Burlet N, Osteoporosis: a still increasing prevalence. Bone, 2006; 38(2 Suppl 1): S4-S9.

20. Sharma S, Tandon VR, Mahajan A, Kour A, Kumar D, Preliminary Screening of Osteoporosis and Osteopenia in urban women from Jammu using calcaneal QUS. Indian J Med Sci., 2006; 60(5): 183-189.

21. Sheu Y, Cauley JA, Wheeler VW, Patrick AL, Bunker $\mathrm{CH}$, Kammerer CM, Zmuda JM, Natural history and correlates of hip BMD loss with aging in men of African ancestry: the Tobago Bone Health Study. $J$ Bone Miner Res., 2009; 24(7): 1290-1298.

22. Suciu M, Suciu L, Vlaia L, Voicu M, Buda V, Drăgan L, Andor M, Vlaia V, Cristescu C, Hîrjău $\mathrm{M}$, The prevalence of inappropriate use of NSAIDs by cardiovascular patients for musculoskeletal disorders. Farmacia, 2020; 68(4): 628-639.

23. Takahashi T, Ishida K, Hirose D, Trunk deformity is associated with a reduction in outdoor activities of daily living and life satisfaction in communitydwelling older people. Osteoporos Int., 2005; 16(3): 273-279.

24. Tarantino U, Iolascon G, Cianferotti L, Masi L, Marcucci G, Giusti F, Marini F, Parri S, Feola M, Rao C, Piccirilli E, Zanetti EB, Cittadini N, Alvaro R, Moretti A, Calafiore D, Toro G, Gimigliano F, Resmini G, Brandi ML, Clinical guidelines for the prevention and treatment of osteoporosis: summary statements and recommendations from the Italian Society for Orthopedics and Traumatology. J Orthop Traumatol., 2017; 18(Suppl 1): 3-36.

25. Teaha DIM, Pascalau NA, Lazar L, Comparative study of the clinical response of patients to different treatment regimens in rheumatoid arthritis. Farmacia, 2019; 67(3): 411-417.

26. Teaha DIM, Pascalau NA, Marcu FM, Lazar L, Comparative Study on the Extent of Damage to Life 
FARMACIA, 2021, Vol. 69, 1

Quality in Rheumatoid Arthritis Patients with Different Therapeutic Strategies. Revista de Chimie, 2019; 70(8): 2908-2911.

27. Tit DM, Bungau S, Iovan C, Nistor Cseppento DC, Endres L, Sava C, Sabau AM, Furau G, Furau C, Effects of the hormone replacement therapy and of soy isoflavones on bone resorption in postmenopause. J Clin Med., 2018; 7(10): 297: 1-13.

28. Tit DM, Pallag A, Iovan C, Furau G, Furau C, Bungau S, Somatic-vegetative symptoms evolution in postmenopausal women treated with phytoestrogens and hormone replacement therapy. Iran J Public Health, 2017; 46(11): 1528-1534.

29. Zehnacker CH, Bemis DA, Effect of weighted exercises on bone mineral density in post menopausal women. A Systematic Review. J Geriatr Phys Ther., 2007; 30(2): 79-88. 